\title{
Vehicle Ownership Restrictions and Fertility in Beijing
}

\author{
Antung A. Liu, Joshua Linn, Ping Qin, and Yang Jun ${ }^{1}$
}

May 2018

\begin{abstract}
This paper studies the effects of vehicle ownership restrictions on fertility. We examine Beijing's license plate lottery system, which began in 2011 and restricts the number of new and used vehicles people can obtain. Leveraging a randomized survey, we show that one unintended consequence of the vehicle restrictions has been to reduce the number of births in the households of lottery entrants between 2011 and 2014. The vehicle restrictions reduce births in households of lottery participants by 35 percent, implying a remarkable 6 percent reduction in births across the entire city. We report changes in household structure and age composition consistent with this change in births.
\end{abstract}

Key words: natural experiment, lottery, vehicle ownership restrictions, fertility

${ }^{1}$ Liu: Indiana University School of Public and Environmental Affairs, Bloomington, Indiana, and the Cheung Kong Graduate School of Business, Beijing, China; aaliu@indiana.edu. Linn: University of Maryland, College Park, Maryland, and Resources for the Future, Washington, DC; 1 inn@umd.edu. Qin: Department of Energy Economics, School of Economics, Renmin University of China, China; pingqin2009@gmail.com. Jun: Beijing Transportation Research Center and Beijing Jiaotong University, China; yangjun218@sina.com. We thank Martha Bailey, Victoria Perez, Dan Sacks, and Kosali Simon for their comments and feedback on this paper. 


\section{Introduction}

Over the last 50 years, the global fertility rate has halved. Worldwide, the average woman has fewer than 2.5 children today, the lowest rate in recorded history (UN 2017). While fertility is of broad concern to the entire world, ${ }^{2}$ it has long been a major policy issue for developing countries in particular (Osili and Long 2008; Bharadwaj 2014; Alfano 2017).

In the wake of China's one-child policy (OCP), the causes and consequences of declining fertility have taken on particular importance. The policy, enacted in 1979, restricted urban couples to one child while allowing couples in other categories to have two children. A growing body of evidence ties the OCP to potentially explosive social problems, including a high malefemale sex ratio(Ding and Hesketh 2006), a rapidly aging labor force (Feng 2012) and less trustworthy, more competitive, and less conscientious individuals (Cameron et al. 2013). Amid the growing concern over declining fertility rates, China began relaxing the OCP in the late 2000s, allowing an increasing number of couples to have two children. While the OCP may have

${ }^{2}$ Governments in 102 countries find that population aging is a "major concern," and 54 countries have enacted policies intended to raise fertility (Brainerd 2014; Lee and Mason 2014). 
accelerated declines in fertility, some hypothesize that China's fertility rates would have declined to current levels even in the absence of the OCP (Zhang 2017). As evidence, many couples choose to have fewer children than the policy permits because of the skyrocketing costs of raising children, including the costs of living space, education, and a clean environment. To the extent that some couples choose not to have children, relaxing the fertility restrictions could have smaller effects on fertility rates than policy makers expect.

Given the increasing attention to the OCP and the costs of declining fertility rates in China, we examine the effects on fertility of another policy: vehicle ownership restrictions in Beijing. Many large cities in East Asia face pervasive traffic congestion and air pollution, and one approach to addressing these issues that has gained traction is the introduction of policies that sharply restrict car ownership. Currently, eight large Chinese cities with a combined population of over 160 million people, along with Singapore, restrict ownership (Yang et al. 2014), with many more considering some form of these restrictions. Beijing implemented a vehicle ownership restriction 
policy starting in January 2011, where only those who win a monthly lottery can purchase a new or used vehicle. ${ }^{3}$

Vehicle ownership restrictions can play a potentially important role in fertility. Social scientists conceptualize the household decision on the number of children in terms of comparing the costs and benefits of increasing the number of children (Becker 1960; Willis 1973). Greenwood et al. (2001) and Coen-Pirani et al. (2010) extend this work to argue that ownership of electrically powered home appliances such as clothes washers increased female labor force participation by reducing the time costs of housework.

We apply this framework to consider the effects of car ownership on fertility. We first use a simple theoretical model to show that restricting vehicle ownership can either increase or decrease fertility rates. On the one hand, cars may increase fertility rates by reducing the cost of

${ }^{3}$ Beijing restricts both vehicle ownership and usage. Liu et al. (2017) examines the effects of vehicle ownership restrictions on labor supply while Yang et al. (2017) studies travel behavior. Wang et al. (2013), Viard and Fu (2015), and Zhong et al. (2017) examine the effects of vehicle usage restrictions on driving, air pollution, and health. 
caring for the children; for example, taking children to activities is much easier with a car than with public transportation. Alternatively, cars may reduce fertility rates by reducing the costs of consumption goods that can substitute for children, such as social activities or recreation time. As a result, while theory suggests that cars play a role in the decision to have children, the net direction and magnitude of that role are empirical matters.

We then provide the first estimate of the effect of car ownership on fertility rates. Car ownership and fertility are complex decisions that depend on many factors; some of these factors are observable in data (such as the ages of the adults), but many others are unobserved (such as expected future income). This makes it challenging to estimate the causal effect of car ownership on fertility. However, because the Beijing vehicle lottery chooses winners randomly, it represents an ideal natural experiment to measure the effects of vehicle ownership on fertility. In this study, winners and losers of this lottery are compared to estimate the effect of vehicle restrictions on the number of post-lottery children born in the three years after the lottery began. ${ }^{4}$

${ }^{4}$ We define pre-lottery children as those born between 2007 and 2010, before the advent of the lottery at the beginning of 2011. We define post-lottery children as those born between 2011 and 2014. The survey that constitutes the primary data set for this paper was conducted at the end of 2014. 
Conditional on entering the lottery, its outcome is randomly assigned, allowing us to examine the causal impact of owning a vehicle without the problems of confounders that usually apply to the decision to purchase a car. We find that each car eliminated by the lottery would have resulted in 0.040 additional births of post-lottery children, a 35 percent increase in fertility rates.

Considering only the within-sample effects of the lottery on fertility, we calculate that the lottery reduced the total number of children born in Beijing during this time by a remarkable 6 percent. Across a number of other specifications, such as alternative definitions of the instrument or isolating fertility effects based on pre-lottery parity, we find no evidence of smaller effects and some evidence for even larger effects.

We document accompanying changes to household structure that are consistent with these changes in fertility. Winning households are more frequently composed of a child with parents and grandparents, whereas losing households are more frequently composed of only husbandwife pairings. The increase in the frequency of grandparents is consistent with a common practice in Chinese society in which grandparents move into households to provide childcare. We also examine the age structure of households and find changes consistent with this narrative.

Prior work has explored the impact of government policies such as direct cash transfers, tax benefits, and paid time off (Gauthier and Hatzius 1997; D'Addio and d'Ercole 2005; Kalwij 2010). These studies consistently find much lower impacts on fertility than our results, even for policies intentionally directed at fertility. However, each of these studies relies on a differencein-difference framework, usually exploiting differences within a country of a policy change such 6 
as an increase in the amount of benefits. These research designs are vulnerable to endogeneity concerns such as omitted variables bias. For example, unobserved shifts in attitudes toward children can be correlated with both new policies and fertility rates. Because we use a natural experiment and randomly select lottery winners, the fertility and household composition of lottery losers are near perfect counterfactuals for the fertility and household composition of winners.

Our results suggest that policies restricting car ownership have an unintended effect of reducing fertility. As we noted above, the OCP may not have been binding for all couples living in Beijing at the start of the lottery. Our results document the importance of car ownership to fertility, lending support to the hypothesis that the rising cost of goods complementary to children strongly reduced fertility. Additionally, to the extent that some couples were bound by the OCP, our estimated effect of vehicle restrictions on fertility—as large as it is — could be understated if the OCP were absent.

More generally, our work suggests that vehicle ownership restrictions may exacerbate the costs of declining fertility rates that many countries face. The results have implications for analysis that relies on population projections, such as estimating the effect of demographics on long-term government revenues and spending. Car ownership can affect fertility independently of income, suggesting that demographers should possibly consider vehicle ownership rates. Our work brings new evidence to the quantity-quality fertility model, because restricting vehicle ownership raises 
the shadow price of child quality, which reduces the quantity of children. Most broadly, our findings draw a new connection between transportation policy and demographic outcomes.

\section{The Theoretical Relationship between Cars and Fertility}

Becker (1960) characterizes children as one type of household good. The household has preferences over children and other goods, and it chooses the utility-maximizing number of children and consumption of other goods, given prices and a budget constraint. In the spirit of this model, and incorporating insights from Greenwood et al. (2001) and Coen-Pirani et al. (2010), we present a simple model of the decision to have a child. We begin with this decision when cars are not available, and then consider the household when a car becomes available.

\subsection{The Decision of a Household without a Car}


Suppose there are two types of goods: market-traded consumption goods $m$ and children $c .{ }^{5}$ The representative household divides its budget between these two types of goods, while also providing labor $L$; when the household is not working, it consumes leisure $l$.

Households receive benefits from consuming goods and leisure:

$$
U=u(m, c, l)
$$

We normalize wages to 1 , so this household is subject to the budget constraint:

$$
p_{m} m+p_{c} c=L
$$

\footnotetext{
${ }^{5}$ Market-traded consumption goods include every type of item except a car; cars are not available to this household because of vehicle ownership restrictions.

In Becker's original model of the decision to have children, he also included a measure for the quality of children. Adding this dimension would alter our model to include individual investments in the quality of children, rather than just the decision to have a child.
} 
In this budget constraint, $p_{m}$ is the price of the consumption good, while $p_{c}$ is the cost of the child.

Now consider the decision to have children. Because of the OCP, the Chinese household can only decide to have either 0 or 1 child. The household chooses to have a child if the marginal utility per dollar for that child exceeds the marginal utility per dollar of the consumption good:

$$
\frac{\partial u / \partial c}{p_{c}}>\frac{\partial u / \partial m}{p_{m}}
$$

\subsection{The Decision of a Household with a Car}

When a car becomes available, the vehicle $V$ has a price $p_{v}$ that occupies a share of the household's budget constraint. However, cars can also affect the prices of the consumption good and of children.

A car can reduce the cost of market-traded consumption goods, because a car facilitates shopping, dining in restaurants, and going to social activities. A car can also lower the cost of raising a child, because a car can be used to bring children to activities; traveling with a child without a car can have high costs. We note that cars can only decrease the costs of other goods, because if travel by car is too costly, the household can always choose not to use the car. 
If the household receives no utility from the act of owning a car, its utility function has the same form as that above. ${ }^{6}$ However, the budget constraint becomes:

$$
\left(p_{m}-p_{m v}\right) m+\left(p_{c}-p_{c v}\right) c+p_{v} V=L
$$

In this new budget constraint, the decrease in price of consumption goods from cars is $p_{m v}$, while the decrease in the cost of a child is $p_{c v}$.

We find that a Chinese household will choose to have a child if:

$$
\frac{\partial u / \partial c}{p_{c}-p_{c v}}>\frac{\partial u / \partial m}{p_{m}-p_{m v}}
$$

${ }^{6} \mathrm{We}$ assume here that there is no direct utility from owning a car. This assumption might be violated if cars signal social status for their owners. Even if cars conferred social status, our analysis of the impact of cars on children would be unchanged so long as cars, consumption goods, and children were separable in utility. If these goods are not separable, our analysis becomes more complex, but the basic qualitative finding would not change. 
Cars affect the decision to have a child in two ways. First, fertility depends on $p_{c v}$ and $p_{m v}$, the effects of cars on the costs of children and consumption goods. If $p_{c v}$ is large, the household is more likely to have a child because of the higher marginal utility of a child relative to cost. If $p_{m v}$ is large, the utility trade-off of a child is higher, and having a child is less likely. Second, cars occupy a share of the budget, reducing the amount of income available to spend on consumption goods and children. In households without children considering the birth of a first child, this effect decreases the quantity of consumption goods purchased, increases the marginal utility of consumption goods, and makes children less likely.

Our theoretical analysis therefore yields an ambiguous effect of vehicle ownership on fertility. In the next sections, we turn to empirical analysis of this question.

\section{Background and Data}

To reduce increasingly severe problems of road congestion and air pollution, Beijing began the vehicle lottery policy in January 2011. Only those who won the lottery were able to purchase either a new or used vehicle. To be eligible to enter the lottery, an applicant must have a driver's license and either possess Beijing identification (hukou) or have paid taxes in Beijing over the previous five years. Drawings are held monthly, and in the first year of the lottery, those applicants who did not win during a given drawing were automatically reenrolled in the next month's lottery. Winners have six months from the time they win to purchase a car. The lottery 
was quickly oversubscribed, and the odds of winning the lottery fell below 2 percent per month by mid-2012 (Yang et al. 2014) and below 1 percent per month in 2017.

Our data are derived from a randomized survey of Beijing conducted by the Beijing Transportation Research Center (BTRC), a government agency tasked with understanding and improving Beijing's transportation systems. Our version of the survey was conducted between September and November 2014 and consists of about 40,000 households selected randomly from a comprehensive list of Beijing addresses. Samples are drawn in proportion to the populations of Beijing's 16 districts.

While the main purpose of the survey is to understand household travel behavior, it also asks respondents to identify the relationship of each member of the household to the head of the household. These questions constitute the primary data set for this study. For each member, year of birth and gender are reported. Because there is no survey question matching parents to children, relationships are inferred using the question identifying each household member's relationship to the head. We use the information about household structure and age composition to complement the analysis of the effects of car ownership on fertility.

Before 2014, the survey did not include questions about the lottery. At our request, the BTRC added questions about the Beijing vehicle lottery to the 2014 survey. Individuals report whether they entered the lottery, when they entered, and whether they won. About 20 percent of households from the survey had at least one member participate in the lottery between 2011 and 2014. 


\section{Empirical Framework and Results}

This section presents two types of evidence on the effects of cars on fertility. The first is a comparison of mean fertility rates and household structure of lottery winners and losers. The second is an econometric analysis of the effects of car ownership on fertility rates and household structure, using lottery outcomes to account for the potential endogeneity of car ownership.

\subsection{Comparison of Lottery Outcomes, Fertility Rates, and Household Structure}

We exploit the randomization of the lottery and use the outcomes of winners to estimate counterfactual fertility rates and household structure for losers. First, to provide context on the lottery sample, in Table 1 we compare households in which someone entered the lottery and households without entrants. Households with entrants are significantly different $(\mathrm{p}<1 \%)$ in almost every aspect. Households with entrants have younger heads of household, more members, and higher car ownership rates and graduation rates. All these differences suggest that households with lottery entrants and households without entrants are not directly comparable. ${ }^{7}$

${ }^{7}$ Differences between lottery entrants and non-entrants do not pose a limitation to our study, which asks how vehicle ownership restrictions affect fertility, because both entrants and nonentrants are subject to the same restrictions limiting new license plates to lottery winners. Under any vehicle ownership restriction policy, some households want to add vehicles while others do not. 
Table 1. Comparison of Households with Lottery Entrants and Households without Entrants

\begin{tabular}{lccc}
\hline \hline & $\begin{array}{c}\text { Households } \\
\text { with entrants }\end{array}$ & $\begin{array}{c}\text { Households without } \\
\text { entrants }\end{array}$ & Difference \\
\cline { 2 - 4 } Age of head of household & 45.7 & 52.5 & -6.8 \\
& $(0.145)$ & $(0.086)$ & $(0.199)$ \\
Number of members & 3.0 & 2.4 & 0.58 \\
& $(0.119)$ & $(0.006)$ & $(0.013)$ \\
Number of working members & 1.7 & 1.0 & 0.67 \\
& $(0.009)$ & $(0.005)$ & $(0.012)$ \\
Number of female members & 1.5 & 1.3 & 0.28 \\
& $(0.009)$ & $(0.004)$ & $(0.009)$ \\
Number of children born between & 0.10 & 0.06 & 0.03 \\
2007 and 2010 & $(0.004)$ & $(0.001)$ & $(0.003)$ \\
Number of children born between & 0.12 & 0.06 & 0.05 \\
2011 and 2014 & $(0.004)$ & $(0.001)$ & $(0.003)$ \\
Number of cars & 0.626 & 0.467 & 0.16 \\
& $(0.008)$ & $(0.003)$ & $(0.008)$ \\
College graduation rate & 0.535 & 0.443 & 0.09 \\
& $(0.004)$ & $(0.002)$ & $(0.005)$ \\
High school graduation rate & 0.470 & 0.370 & 0.10 \\
& $(0.004)$ & $(0.002)$ & $(0.005)$ \\
\hline
\end{tabular}

Notes: The table reports characteristics of the households of lottery entrants $(N=7,041)$ and those without any lottery entrant $(N=32,966)$. The first two columns report means with standard deviations in parentheses, and the third column reports the difference with standard error in parentheses. All differences are statistically significant at the $1 \%$ level.

We next examine the pool of entrants by comparing the characteristics of winners and losers of the lottery in Table 2. Only those characteristics that are unlikely to be affected by the outcome of the lottery are compared. Unlike the prior comparison between households with entrants and households without entrants, comparing winners and losers suggests no statistically significant differences in preexisting characteristics at even the 10 percent level. This is consistent with a successful randomization between winners and losers enacted by the license plate lottery.

Table 2. Comparability of Individuals Winning and Not Winning the Lottery 


\begin{tabular}{lccc}
\hline \hline & Winners & Losers & Difference \\
\hline \hline Female & \multicolumn{3}{c}{ Lottery Entrants } \\
& 0.389 & 0.409 & -0.020 \\
Birth year & $(0.017)$ & $(0.006)$ & $(0.019)$ \\
& 1975.8 & 1975.8 & 0.0 \\
High school graduation rate & $(0.4)$ & $(0.1)$ & $(0.4)$ \\
& 0.709 & 0.702 & 0.007 \\
College graduation rate & $(.016)$ & $(0.005)$ & $(0.017)$ \\
& 0.629 & 0.624 & 0.005 \\
$N$ & $(0.017)$ & $(0.006)$ & $(0.018)$ \\
& 779 & 7,278 & \\
\hline Female & 0.484 & 0.489 & -0.005 \\
& $(0.018)$ & $(0.006)$ & $(0.019)$ \\
Birth year & 1967.8 & 1968.3 & -0.5 \\
& $(0.4)$ & $(0.1)$ & $(0.5)$ \\
High school graduation rate & 0.521 & 0.536 & -0.015 \\
& $(0.018)$ & $(0.006)$ & $(0.019)$ \\
College graduation rate & 0.449 & 0.466 & -0.017 \\
& $(0.018)$ & $(0.006)$ & $(0.019)$ \\
$N$ & 779 & 7,278 & \\
\hline \hline
\end{tabular}

Note: None of these characteristics differ at the $1 \%, 5 \%$, or $10 \%$ level of statistical significance.

The comparability of winners and losers suggests that comparing mean fertility rates between winners and losers identifies the causal effect of winning on fertility. Figure 1 presents the mean number of post-lottery and pre-lottery children in the households of lottery winners and losers. Figure 1 shows that households of lottery winners have 0.035 more post-lottery children than households of lottery losers, a large and statistically significant increase of 30 percent over the mean of lottery losers.

Figure 1. Mean Numbers of Post-lottery and Pre-lottery Children in the Households of Lottery Winners and Losers 


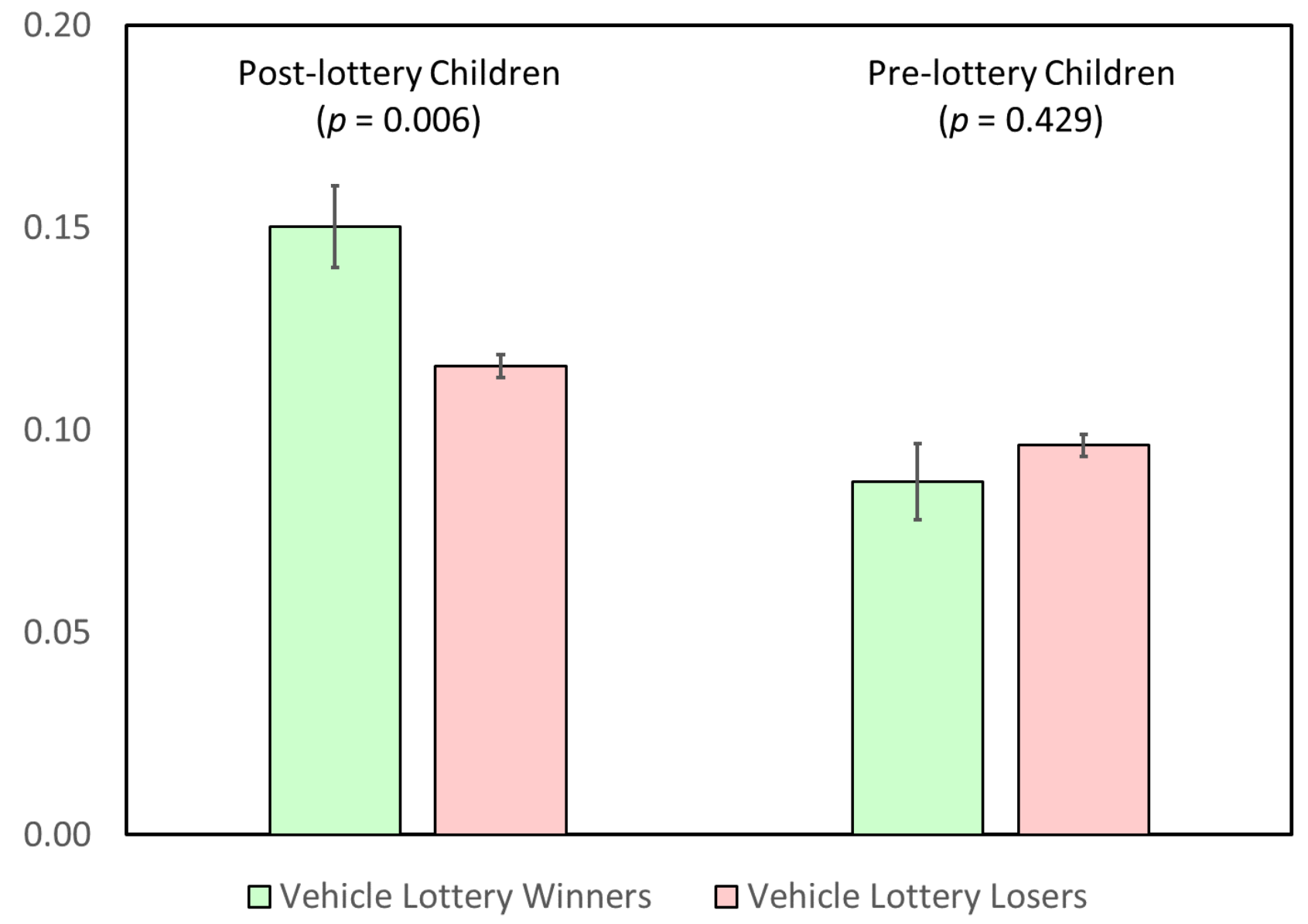

Notes: Depicted is the average number of post-lottery children ( \pm s.e.), defined as those children in the household born between 2011 and 2014, and the average number of pre-lottery children ( \pm s.e.), defined as children born between 2007 and 2010. Children are divided into groups for lottery winners $(N=779)$ and lottery losers $(N=7,278)$. The reported $p$-values are from statistical tests of equality.

Pre-lottery children represent a placebo check for our analysis, because the 2011 lottery should not affect the number of children already born. Indeed, the difference in the number of pre- 
lottery children is statistically insignificant; its point estimate is about one-quarter the size of the difference in post-lottery children.

We expect changes in fertility to affect household composition, so we next turn to the effect of vehicle restrictions on household structure. This provides evidence complementary to our results on fertility.

Before we present our analysis on the changes in household structure, it is important to consider what changes in household structure should be expected if vehicle ownership increases fertility. Figure 2 shows every household structure of lottery winners and losers with more than a 1 percent prevalence, with the green bars representing the household structures of the winners and the blue bars representing those of the losers. Of the 10 household structures meeting this criterion, 6 already have a child present. Because of China's OCP, we would not expect additional children in these households. In two of these household structures (single occupant, adult with 2 parents), we would not expect winning to affect fertility. ${ }^{8}$ In only two of these

${ }^{8}$ Chinese society requires families to obtain a reproduction permit before giving birth; these permits are routinely denied to single men or women, resulting in very few families with a single mother or father and child. 
structures (husband/wife and husband/wife/elderly parent) would we expect changes in fertility to reduce their prevalence, although households with husband/wife/elderly parent make up only 2 percent of the households of losers.

Figure 2. Household Structures of Lottery Winners and Losers

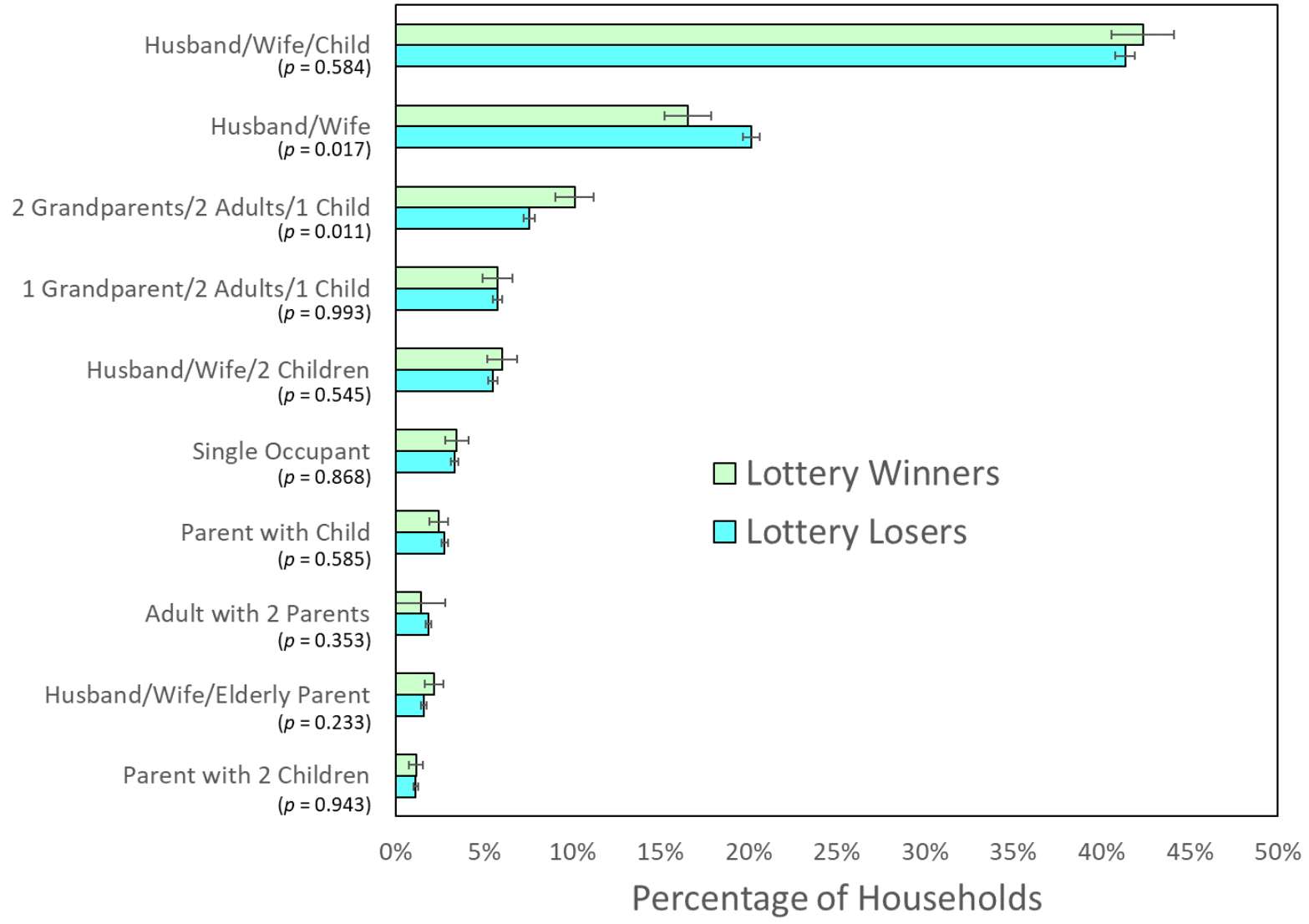

Notes: The percentages ( \pm s.e.) of lottery winners $(N=779)$ and lottery losers $(N=7,278)$ with a given family structure. We include all family structures with prevalences above 1 percent in Beijing, accounting in total for 91 percent of losing households and 87 percent of winning households. Error bars and $p$-values are constructed as in Figure 1. 
As expected, the prevalence of households with only a husband and wife is lower for lottery winners by a large and statistically significant amount. This type of household is less common in winning households than in losing households by 3.6 percentage points, a statistically significant decrease $(p<5 \%)$ of about 18 percent over the frequency of losers.

If obtaining a car raises fertility, households should transition from those with a husband and wife to those with a husband, wife, and child. There are four households with this combination: husband/wife/child, 2 grandparents/2 adults/ 1 child, 1 grandparent/ 2 adults/ 1 child, and husband/wife/2 children.

As expected, the frequency of households with husband/wife/child and husband/wife/2 children increases, although our standard errors do not allow us to measure these differences with precision. The largest change occurs in households with 2 grandparents/2 adults/ 1 child; this type is 2.6 percentage points more common in winning households, a statistically significant increase ( $p<5 \%$ ) of 34 percent over households of lottery losers. Cars might increase this type of family structure for two reasons. First, in Chinese society, the prevalence of two-income households creates a common cultural practice where grandparents live with the family to help with childcare when a baby is born. Second, cars can provide transportation options for the elderly, making it easier for grandparents to help care for children.

We see that the decrease from losing households to winning households in the frequency of husband/wife household types (3.6 percentage points) is almost exactly equal to the combined increases in the frequency of husband/wife/child households (1.0 percentage points) and 2 20 
grandparents/2 adults/ 1 child households ( 2.6 percentage points). This suggests a clear transition in types between the households of lottery losers and winners caused by vehicle ownership.

In summary, we see a statistically significant decrease in the prevalence of households with husband/wife and a statistically significant increase in the prevalence of households with 2 grandparents/ 2 adults/ 1 child. These results are entirely consistent with an increase in fertility after considering China's laws and culture, including the OCP, its heavy restrictions on single men and women bearing children, and the cultural practice of grandparents moving in with new parents.

Finally, we examine the age structure of households of lottery winners and losers in Figure 3. The changes in fertility and family structure that are documented above are also reflected in the number of people in each age group living in these households. Winning households have statistically significant increases in the number of people ages 0 to $3(p<1 \%)$ and changes of borderline statistical significance in the number of people who are 51 years or older $(p<10 \%)$. All other age groups are statistically identical.

Figure 3. Age Structure of Households of Lottery Winners and Losers 


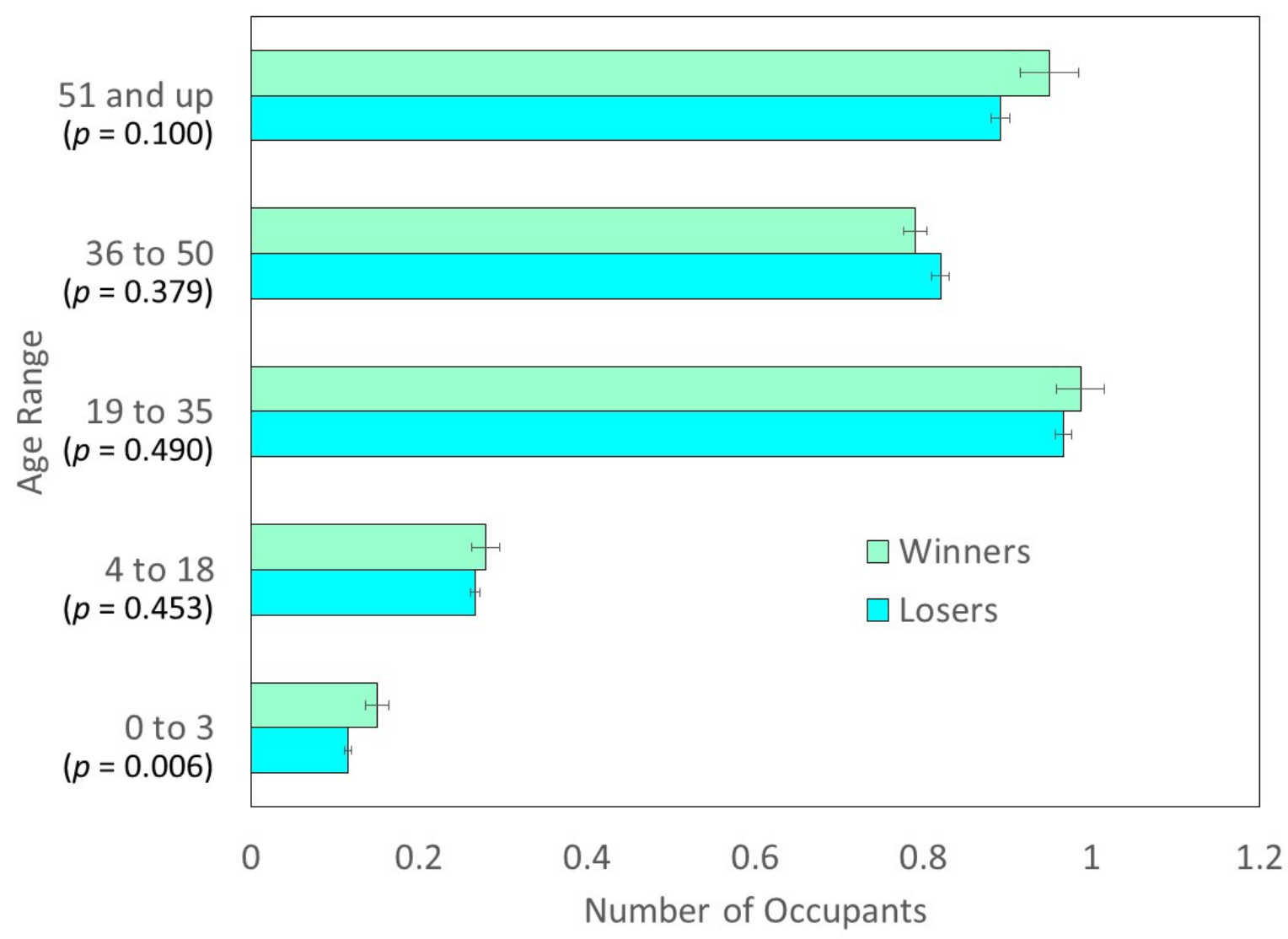

Note: This figure shows the number of occupants $( \pm$ s.e. $)$ in households of winners $(N=779)$ and losers $(N=7,278)$, classified by age. 


\subsection{Econometric Evidence on the Effects of Cars on Fertility and Household Structure}

While the above figures show the effect of winning the lottery on fertility, policymakers may be more interested in how vehicle restrictions and the number of cars owned by households affect fertility. However, a regression of fertility on the number of cars owned by the household would yield biased estimates if car ownership is correlated with unobserved factors that affect fertility. For example, a household expecting its income to increase may be more likely to obtain a car and have a child. For this reason, we estimate an instrumental variables (IV) model in which we replace the actual number of cars with the number of cars predicted by whether the entrant won or lost the lottery. The validity of the IV is supported by Table 2, which documents the comparability of winners and losers and suggests that the lottery outcome is uncorrelated with unobserved variables that affect car ownership and fertility.

We employ the following specifications:

$$
\begin{aligned}
& Y_{i}=\mu+\alpha_{1} \widehat{N}_{l}+\eta_{i}+X_{i} \alpha_{2}+\epsilon_{i} \\
& N_{i}=\lambda+\beta_{1}(W)_{i}+\eta_{i}+X_{i} \beta_{2}+\mu_{i}
\end{aligned}
$$

In these equations, $Y_{i}$ is the outcome variable of interest for individual $i$. Outcomes of interest include the number of post-lottery children, the number of pre-lottery children, and indicator variables for the three most prevalent types of family structures (Figure 2). The variable $N_{i}$ represents the number of cars in household $i$. We insert the fitted value of $N_{i}$ from equation (2) into equation (1), adjusting standard errors appropriately. The variable $W_{i}$ represents the lottery 23 
status of $i$ : whether the individual won or lost the lottery. Only lottery entrants are included in these regressions. Observations are at the individual rather than the household level because the randomization of the lottery occurs at the individual level. The covariates $X_{i}$ include observable characteristics that should be unaffected by the lottery: the age of the individual, age-squared, whether the individual is male, and fixed effects for the day the entrant was interviewed and the education level of the entrant.

Importantly, each regression includes $\eta_{i}$, a set of fixed effects for an entrant's lottery entry date. These are necessary because earlier entrants have more chances to win the lottery and may have stronger unobserved preferences for cars. The presence of this covariate implies that the coefficient on number of cars compares outcomes for lottery winners and losers who entered at the same time, controlling for possible unobserved factors correlated with entry date. ${ }^{9}$

${ }^{9}$ Although this specification controls for entry date, it does not explicitly control for winning date. As we discuss in section 4.4.7., if renewing lottery applications is endogenous and correlated with preferences for having children, this could bias the main estimates. We show below that this potential source of bias does not appear to be important in practice. 
Our first-stage regression results of equation (2) are presented in Table 3. The coefficient estimate from the first row of this table indicates that lottery winners have 0.636 more cars per household than losers, a large and statistically significant result. The number of cars added is less than one for several reasons, including the fact that not every lottery winner chooses to purchase a car. Almost 10 percent of lottery winners do not choose to purchase a car. Importantly, if a person wins the lottery, the license plate is not legally transferable. Another explanation for the magnitude of the lottery coefficient is that some losing households may have been able to obtain a car even without winning the lottery, a possibility that does not bias our result so long as the lottery drawing was random.

Table 3. First-Stage Regression on the Number of Cars

Number of Cars

Won the lottery $0.636^{* * *}$

Age / 100

(Age * age) $/ 10,000$

Is male $-0.167^{* * *}$ 
Notes: Regressions include only lottery entrants. All regressions include fixed effects for the day of the week of the interview, for the education level of the entrant, and for the month of entering the lottery. Standard errors are clustered at the city district level.

$* p<0.10, * * p<0.05, * * * p<0.01$.

The IV results are presented in Table 4. This table affirms the positive causal impacts of cars on the number of children and family structure. As shown in column 1, each car results in 0.040 additional post-lottery children born between 2011 and 2014, a 34 percent increase over the average of 0.116 post-lottery children in households of lottery losers (see Figure 1). Because people may have won the lottery at different times, but we observe them only once at the end of 2014, winners have owned cars for different lengths of time when we observe them. This estimate should be interpreted as the duration-weighted average treatment effect on fertility of adding a car.

Table 4. IV Regressions on Children and Family Structure

\begin{tabular}{|c|c|c|c|c|c|}
\hline & \multicolumn{2}{|c|}{ Regressions on Children } & \multicolumn{3}{|c|}{ Regressions on Family Structure } \\
\hline & $\begin{array}{l}\text { Number of } \\
\text { Post-lottery } \\
\text { children } \\
\text { (1) }\end{array}$ & $\begin{array}{l}\text { Number of } \\
\text { Pre-Lottery } \\
\text { children } \\
\text { (2) }\end{array}$ & $\begin{array}{c}\text { Husband/ } \\
\text { wife/child } \\
\text { (3) }\end{array}$ & $\begin{array}{l}\text { Husband/ } \\
\text { wife } \\
\text { (4) }\end{array}$ & $\begin{array}{l}2 \text { Grand- } \\
\text { parents/ } 2 \\
\text { adults/1 } \\
\text { child } \\
(5)\end{array}$ \\
\hline Number of cars & $0.040 * *$ & -0.013 & 0.026 & $-0.050 * *$ & $0.033 * *$ \\
\hline
\end{tabular}




\begin{tabular}{lccccc} 
& $(0.017)$ & $(0.016$ & $(0.037)$ & $(0.019)$ & $(0.015)$ \\
Age / 100 & -0.002 & $1.699 * * *$ & $1.147^{*}$ & -0.019 & $0.271^{*}$ \\
& $(0.421)$ & $(0.495)$ & $(0.634)$ & $(0.301)$ & $(0.158)$ \\
$($ Age * age) / 10,000 & -0.425 & $-2.074 * * *$ & $-1.664 * *$ & $1.088 * * *$ & $-0.510^{* * *}$ \\
& $(0.496)$ & $(0.571)$ & $(0.740)$ & $(0.411)$ & $(0.170)$ \\
Is male & 0.011 & $-0.017 * *$ & -0.009 & 0.008 & 0.007 \\
& $(0.010)$ & $(0.007)$ & $(0.008)$ & $(0.010)$ & $(0.009)$ \\
$N$ & 8,057 & 8,057 & 8,057 & 8,057 & 8,057 \\
$R^{2}$ & 0.040 & 0.019 & 0.017 & 0.074 & 0.033 \\
\hline \hline
\end{tabular}

Notes: Estimation results of equations 1 and 2. In each regression, covariates also include fixed effects for the day of the week the entrant was interviewed and the education level of the entrant. The variable of interest is the number of cars in individual $i$ 's household. We instrument for this variable by whether the individual won the Beijing vehicle lottery. Only lottery entrants are included. Columns 1 and 2 report the number of children born between 2011 and 2014 and between 2007 and 2010, respectively. Columns 3 through 5 present regressions where the dependent variable is a dummy for whether a lottery entrant's household had the makeup indicated in the column heading at the time of the survey, in 2014.

$* p<0.10, * * p<0.05, * * * p<0.01$. 
The first stage $F$-statistic is 379 , reducing concerns about weak instruments bias. The number of cars has a small and statistically insignificant impact on the number of older children (column 2), affirming the validity of the research design.

Columns 3 through 5 of this table show the impacts of cars on the three most common forms of family structure. Just as was found in Figure 2, the IV estimates are consistent with the idea that obtaining a car caused families to shift out of husband/wife pairings and into households with 2 grandparents $/ 2$ adults/ 1 child. Each car causes a decrease in husband/wife only households and an increase in the number of households with husband/wife/child or 2 grandparents/2 adults/1 child. Analogous to the graphical results, the decrease in the percentage of husband/wife households (5.0 percentage points) is similar in size to the combined increases of the frequency of husband/wife/child households (2.6 percentage points) and 2 grandparents/2 adults/ 1 child households (3.3 percentage points). IV evidence on family structure is also strongly supportive of changes in fertility caused by vehicle ownership.

\subsection{Implications of the IV Estimates for Aggregate Fertility}

To provide context for the effect of the lottery on fertility, we calculate the change in babies born during the lottery period in the city of Beijing. To perform this calculation, we assume that lottery losers would have behaved like winners if they had won. This assumption is supported by the randomness of the lottery instrument and by the comparability in other characteristics 
between winners and losers. ${ }^{10} \mathrm{We}$ also require the assumption that non-entrant families would have had the same number of children in the absence of the lottery — that is, the lottery did not affect their fertility decisions. This assumption is reasonable since the decision to have a child for non-entrants is plausibly unaffected by the existence of vehicle restrictions - that is, the lottery does not directly affect the benefits and costs of having children for households that do not participate in the lottery.

We begin our estimate of the effects of vehicle restrictions on fertility by calculating how many post-lottery children lottery losers would have had if they had been free to purchase cars. Table 4 suggests that lottery losers would have had 0.040 additional post-lottery children per car, about 35 percent more than the 0.116 that they actually had. We multiply this figure by the 0.636 cars per entrant that lottery losers would have had (Table 3). Lottery losers would have had 0.141 post-lottery children per entrant, compared with the 0.150 post-lottery children per entrant that lottery winners had. Since there are 7,278 lottery losers, vehicle restrictions reduced births by $(7,278 * 0.040 * 0.636)=185$ post-lottery children.

${ }^{10}$ Implicitly, we assume that having a child does not depend on aggregate factors affected by the lottery, such as traffic congestion. 
The original BTRC survey, a random sample from the city of Beijing, included a total of 47,319 women ages 18 and over. In all, this sample has 2,891 post-lottery children, but in the absence of vehicle restrictions, there would have been $(2,891+185)=3,076$ post-lottery children. In sum, vehicle restrictions reduced the number of children born between 2011 and 2014 by $(185 / 3076)$ * $100 \%=6 \%$ (s.e. $2.6 \%$ ), a large decrease. 


\subsection{Tests of Robustness and Other Results}

In this section, we report additional results supporting our main findings and enriching our narrative of the impacts of cars on fertility.

\subsubsection{Definitions of Children Affected by Cars}

In our central results, we define post-lottery children as those born between 2011, the year the vehicle lottery began, and 2014, the year the survey was taken. This measure has the benefit of being exogenous to the timing of the decision to enter the lottery but may introduce measurement error by including children born in years before any person in the household entered the lottery. A second possible definition would include children born in the year any household member entered the lottery or any year after that year. This group is likely to include households where a member won the lottery and the mother became pregnant but is subject to the concern that the mother may have become pregnant in the months before family members entered the lottery. A third possible definition would include children born only in the years after any person in the household entered the vehicle lottery. This group is likely to have the least measurement error, because these post-lottery children are the most likely to be affected by lottery outcomes. However, it is subject to the possible concern that families who enter the lottery earlier have a longer time between winning and the survey date in which to have children. As noted above, this consideration affects the interpretation of the estimate but does not imply that it is biased. 
In order to allay possible concerns that the main conclusions are sensitive to the definition of post-lottery children, all three definitions are graphed in Figure 4. Because the first and second definitions are more inclusive, each of these definitions shows more children in the households of both winners and losers. Each of these definitions shows a large and statistically significant difference between lottery winners and losers. Finally, if lottery entry date is correlated with the desire to have children, differences between winners and losers should be greater under the second and third definitions. Indeed, these definitions show greater differences between winners and losers than the first. 
Figure 4. Comparison of Different Definitions of Postlottery Children

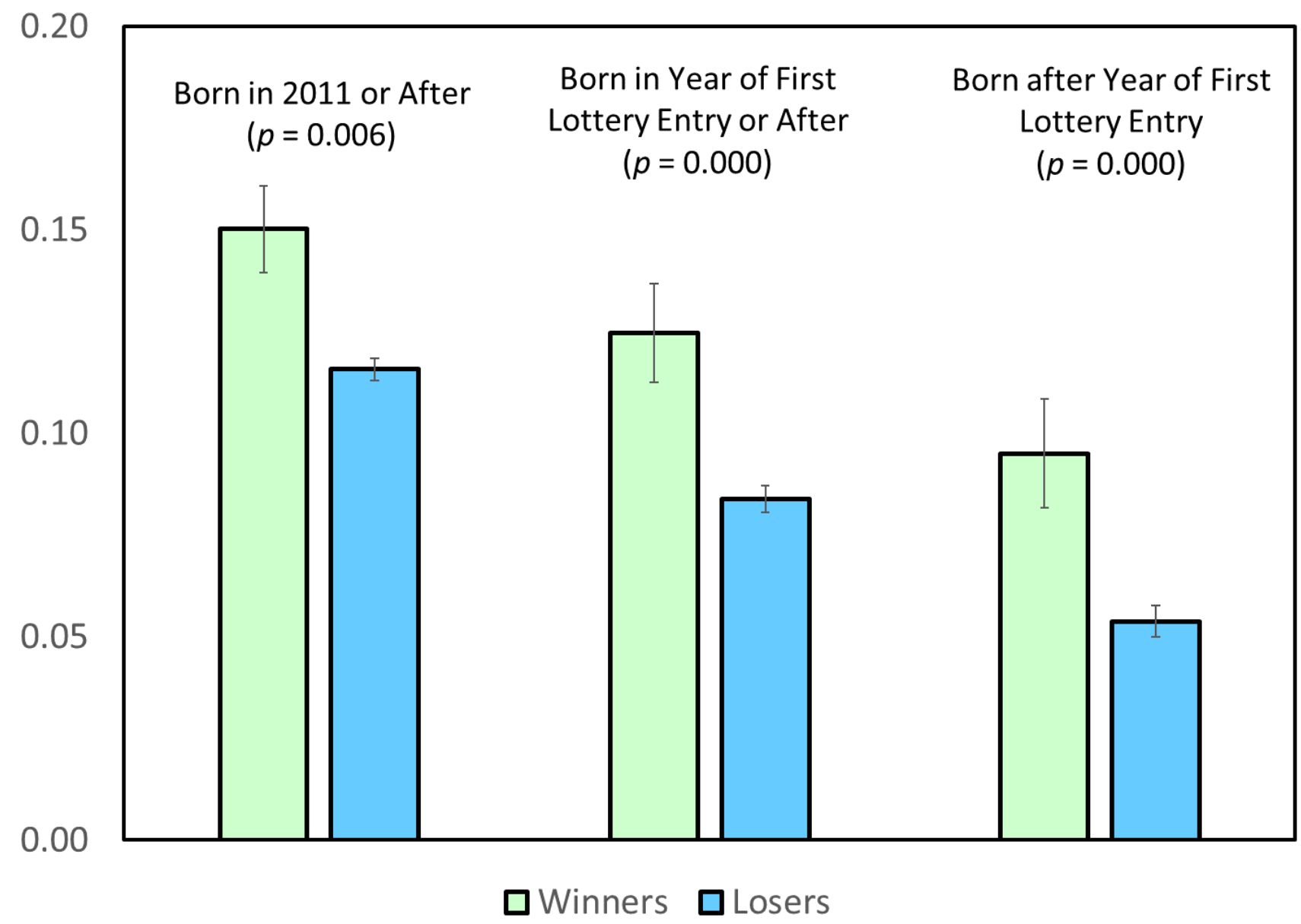

Note: This figure shows the number of postlottery children ( \pm s.e.) in households of winners $(N=$ $779)$ and losers $(N=7,278)$, classified by definition.

If we use the first definition of post-lottery children, winners have 0.035 more post-lottery children than losers. If we use the second or third definition, winners have 0.041 more postlottery children than losers. Generally speaking, all three possible definitions are highly supportive of large differences in fertility between lottery winners and losers. 


\subsubsection{Effects of Vehicles by Year and the Presence of Children Already in the Home}

Because of the OCP, changes in fertility as a result of cars are more likely to occur in households that do not already have children than in households that already have children. We verify this by dividing the surveyed lottery entrants into subgroups based on whether the entrant had a child between the ages of 4 and 18 at the time of the 2014 survey (that is, born before the 2011 lottery but not yet an adult). To examine how fertility increases are distributed across lottery entrants, we further divide our sample according to year of lottery entry. Table 5 presents our examination of the differences in birthrates for each of these subgroups.

Table 5. Difference in Children Born between 2011 and 2014, by Subgroup

\begin{tabular}{lccc}
\hline \hline & Winners & Losers & Difference \\
\hline \hline & \multicolumn{2}{c}{ Lottery } & entrants $(N=8,057)$ \\
\hline All entrants & 0.150 & 0.116 & $0.035^{* * *}$ \\
Entrants with children age 4 to 18 & $(0.013)$ & $(0.004)$ & $(0.012)$ \\
& 0.023 & 0.018 & 0.005 \\
Entrants with no children age 4 to 18 & $(0.010)$ & $(0.003)$ & $(0.010)$ \\
& 0.198 & 0.150 & $0.048^{* * *}$ \\
& $(0.018)$ & $(0.005)$ & $(0.016)$ \\
\hline All entrants & Entrants from $2011(N=2,151)$ \\
& 0.145 & 0.134 & 0.011 \\
Entrants with children age 4 to 18 & $(0.019)$ & $(0.008)$ & $(0.021)$ \\
& 0.020 & 0.019 & 0.000 \\
Entrants with no children age 4 to 18 & $(0.014)$ & $(0.007)$ & $(0.016)$ \\
& 0.197 & 0.174 & 0.023 \\
& $(0.026)$ & $(0.011)$ & $(0.028)$ \\
\hline All entrants & Entrants from $2012(N=2,575)$ \\
Entrants with children age 4 to 18 & 0.157 & 0.118 & $0.039^{*}$ \\
& $(0.023)$ & $(0.007)$ & $(0.021)$ \\
Entrants with no children age 4 to 18 & 0.045 & 0.014 & $0.031^{*}$ \\
& $(0.025)$ & $(0.005)$ & $(0.017)$ \\
& 0.193 & 0.154 & 0.040 \\
& $(0.029)$ & $(0.009)$ & $(0.028)$ \\
\hline
\end{tabular}


Entrants from $2013(N=2,134)$

\begin{tabular}{lccc}
\hline All entrants & 0.159 & 0.113 & 0.046 \\
& $(0.034)$ & $(0.007)$ & $(0.029)$ \\
Entrants with children age 4 to 18 & 0.000 & 0.018 & -0.018 \\
& $(0.000)$ & $(0.007)$ & $(0.024)$ \\
Entrants with no children age 4 to 18 & 0.22 & 0.144 & $0.077^{* *}$ \\
& $(0.045)$ & $(0.009)$ & $(0.038)$ \\
\hline All entrants & Entrants from $2014(N=1,197)$ \\
Entrants with children age 4 to 18 & 0.111 & 0.088 & 0.023 \\
& $(0.062)$ & $(0.008)$ & $(0.056)$ \\
Entrants with no children age 4 to 18 & 0.000 & 0.024 & -0.024 \\
& $(0.000)$ & $(0.010)$ & $(0.061)$ \\
& 0.158 & 0.113 & 0.045 \\
\hline \hline
\end{tabular}

The first panel shows that across all four years, households with no children age 4 to 18 account for the entire fertility increase observed between winners and losers. In subsequent panels, the first row shows that lottery winners from every entry year had more children born between 2011 and 2014 than lottery losers. The second and third rows of each panel show that births are largely concentrated among entrants with no children age 4 to 18 . Additionally, the birthrates of lottery winners with no children age 4 to 18 are generally higher than birthrates of lottery losers. Most of these annual differences are not statistically different due to the small sample size. The main IV estimates characterize the average effects of car ownership across all lottery participants. Because of the OCP, we expect car ownership to have a larger effect on fertility among households that do not have children prior to the lottery. To test this hypothesis, we use the presence of a child between the ages of 4 and 18 as a pre-determined characteristic in an IV 
specification involving the interaction of lottery status and whether the entrant had a child of this age:

$$
\begin{aligned}
& Y_{i}=\mu+\gamma_{1} \widehat{N_{l}}+\gamma_{1} \widehat{N_{l} P_{l}}+\eta_{i}+\left(X_{i} * P_{i}\right) \gamma_{1}+P_{i}+\epsilon_{i} \\
& N_{i}=\lambda+\delta_{1} W_{i}+\delta_{2} W_{i} P_{i}+\eta_{i}+\left(X_{i} * P_{i}\right) \delta_{3}+P_{i}+\mu_{i} \\
& N_{i} P_{i}=\epsilon+\theta_{1} W_{i}+\theta_{2} W_{i} P_{i}+\eta_{i}+\left(X_{i} * P_{i}\right) \theta_{3}+P_{i}+\omega_{i}
\end{aligned}
$$

In these equations, all the variables are defined as in equations (1) and (2) except $P_{i}$, which represents a dummy variable indicating whether the entrant had a household member between the ages of 4 and 18 . Because this is a characteristic determined prior to the lottery, it is exogenous, and we can use the interaction of this characteristic with other predetermined characteristics, such as age, gender, and whether the individual won the lottery, as additional instrumental variables. 
Our results are presented in Table $6 .{ }^{11}$ The effect of cars on households who do not have a child age 4 to 18 can be seen in the bottom row of this table. The magnitude of this coefficient is similar to that of table 4, and suggests that cars increase fertility. Related to this increase in fertility, we see a decrease in frequency of households with only husband/wife pairings.

Coefficients in the second row of this table suggest that cars have statistically insignificant effects on fertility for households who already have children age 4 to 18 . This is the pattern expected under the OCP. Columns 2 through 4 of Table 6 enrich our results of the effect of cars on family structure. The fourth column of this second row suggests that cars may increase the number of households with two grandparents. In these families, cars may facilitate the ability of the elderly to provide childcare, encouraging families with children to bring in their parents. This suggests that cars can affect household structure in other ways than via fertility.

${ }^{11}$ Unlike Table 4, Table 6 does not include a regression where the number of pre-lottery children is a dependent variable. This is because we wished to avoid regressions where both the righthand-side and left-hand-side variables included these children. 
In sum, these tables confirm that the changes in fertility rates that we observed in Table 4 are concentrated among lottery entrants who have no children born before the advent of the lottery. Additionally, we learn that cars can cause important changes in household structure, even in those families that already have children.

Table 6. IV Regressions on Children and Family Structure, Including Interaction Terms for Not Having Children Age 4 to 18

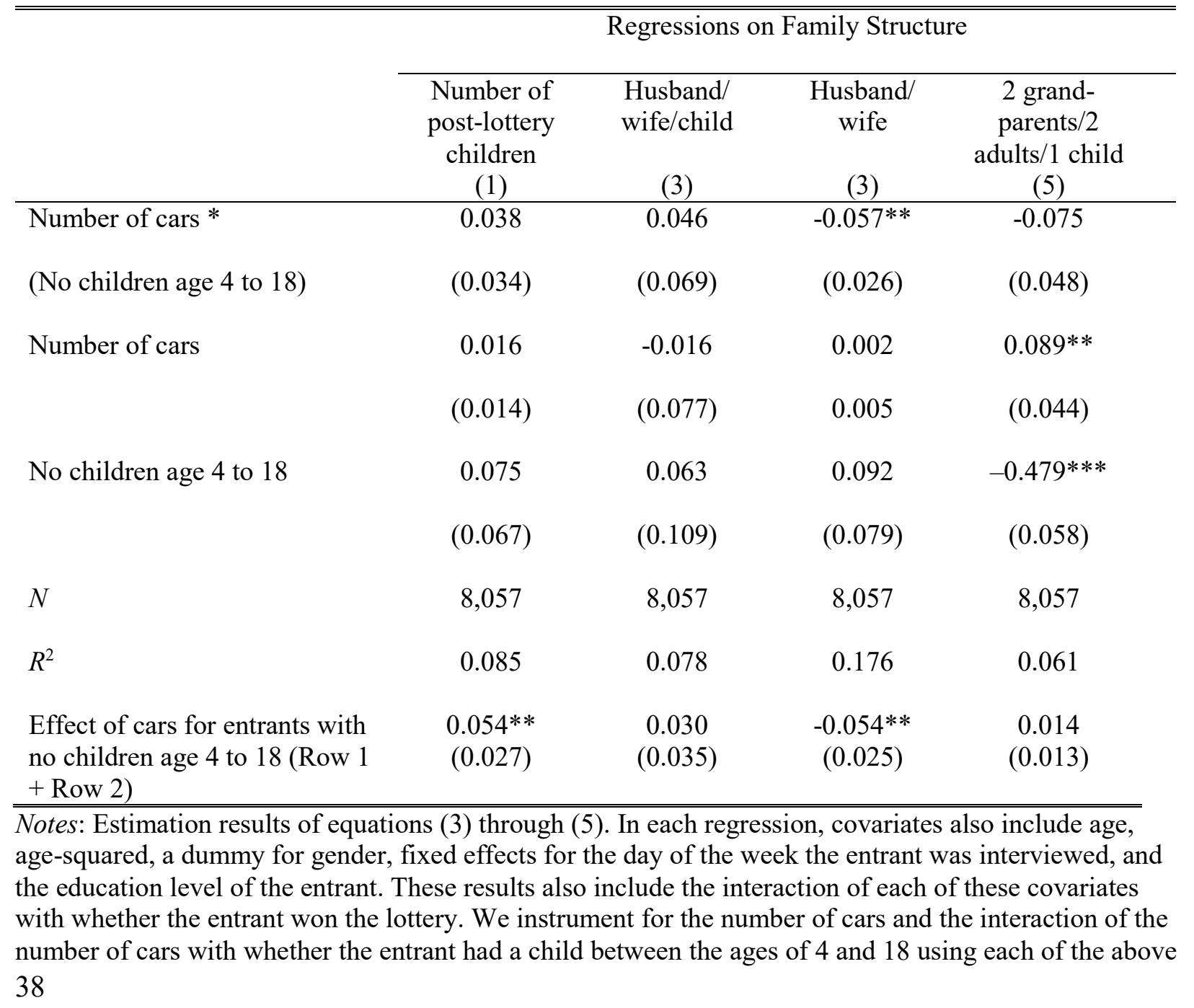


variables, along with whether the individual won the Beijing vehicle lottery, and the interaction of winning with whether the entrant had a child between the ages of 4 and 18. Only lottery entrants are included.

$* p<0.10, * * p<0.05, * * * p<0.01$.

\subsubsection{Effects of Cars on Gender Composition}

Since we observe the genders of the children, we can also examine the effect of vehicle restrictions on the sex ratio. The sex ratio is an important issue in China because the OCP led many families to practice sex selection, leading to highly imbalanced male-female ratios (Ebenstein 2010).

We can see the gender effects of vehicle restrictions in Figure 5. The number of children born between 2011 and 2014 is presented in the left two columns. Among lottery-losing households, there is virtually no difference in the numbers of boys and girls. For lottery-winning households, the number of boys is larger than the number of girls, although this difference is not statistically significant.

Figure 5. Gender Effects of Vehicle Restrictions 


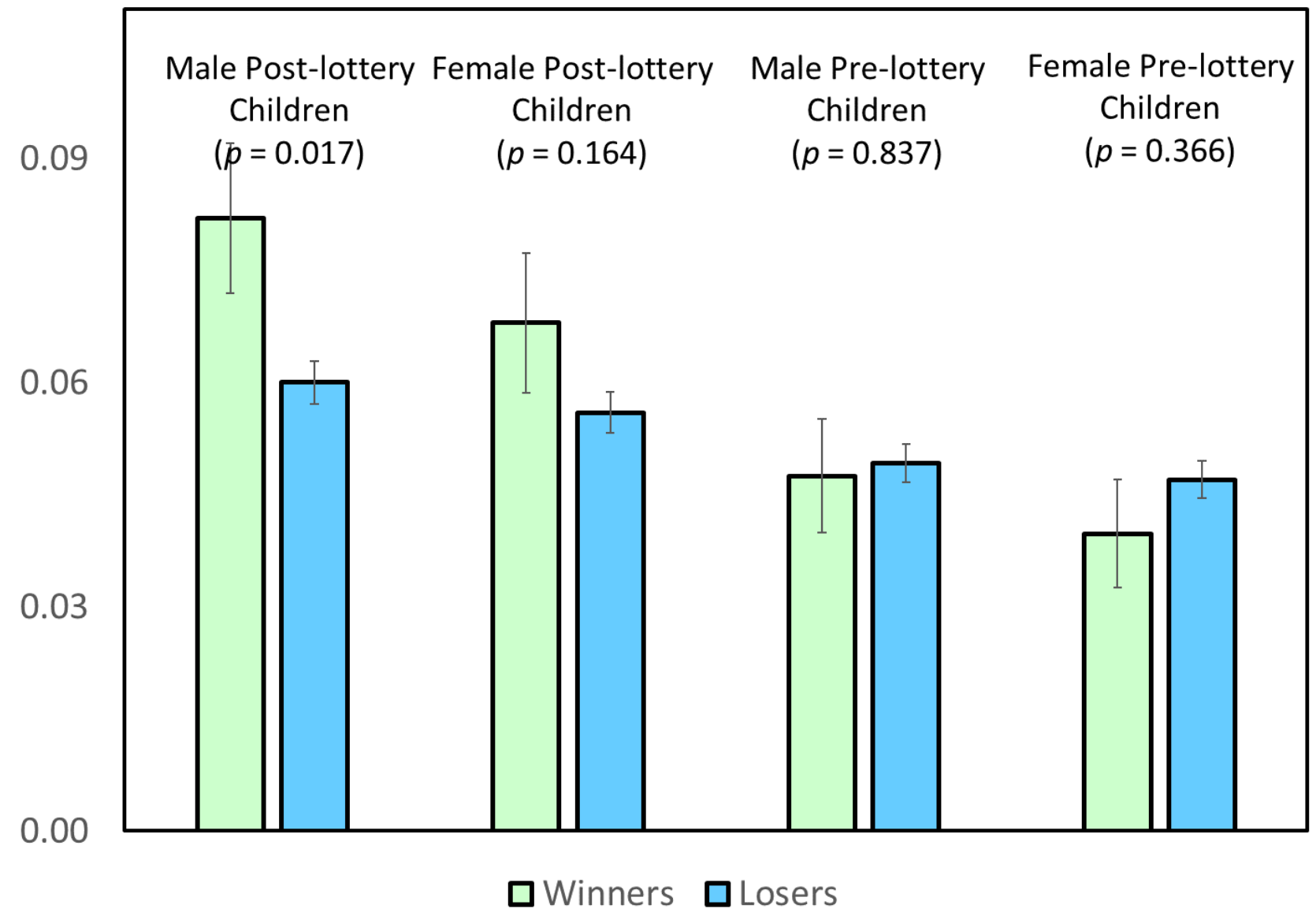

Note: This figure shows the number of post-lottery children ( \pm s.e. $)$, defined as children born between 2011 and 2014, and pre-lottery children ( \pm s.e.), defined as children born between 2007 and 2010, in households of winners $(N=779)$ and losers $(N=7,278)$, by gender.

The number of children born between 2007 and 2010 is presented in the right two columns as a placebo test. We can see from this placebo test that differences between the number of both male and female pre-lottery children for winners and those of losers are small and statistically insignificant. 
To summarize: our point estimates suggest that births by lottery-winning households are biased toward more boys. However, this difference is not statistically significant at conventional levels.

\subsubsection{Probit Effects of Cars on Whether a Child Is Born}

Because most families in China have only one child, we can also run an IV probit model with the same independent variables as equations (1) and (2), but where the dependent variable is whether the lottery entrant has a child born after 2011 in the household. We find that each car increases the probability that the lottery entrant has a post-lottery child by 19.1 percentage points and has no statistically significant effect on the probability of having a pre-lottery child. The probit results are consistent with the results reported in Table 4 (available on request).

\subsubsection{Hazard Model Analysis of Birthing a Child}

Because most families in China have only one child, we can also conduct a hazard model analysis comparing lottery winners and losers where having any post-lottery child is the dependent variable. We present our graph of this hazard analysis in Figure 6, and Cox regressions on this probability in Table 7.

Column 1 of Table 7 is the simplest version of the model, and estimates without covariates the effect of winning the lottery on having a child. The coefficient on winning the lottery, 0.294, suggests that winning the lottery increases an entrant's chance of having a post-lottery child by $34 \%$, almost identical to the $30 \%$ increase in post-lottery children for winners over losers that we 
found in Figure 1 of the paper. When we add additional covariates in column 2, we find that winning the lottery raises an entrant's chance of having a post-lottery child by $24 \%$. When we interact the number of pre-lottery children with the lottery outcome, the coefficients suggest that, while winning the lottery has statistically insignificant effect on having post-lottery children for those who already have pre-lottery children, it raises the probability for those who do not have pre-lottery children by $22 \%$. In sum, estimates from a hazard model analysis are generally consistent with those from the rest of the paper.

Figure 6. Hazard Model Analysis of Lottery Winners and Lottery Losers in Having a Postlottery Child

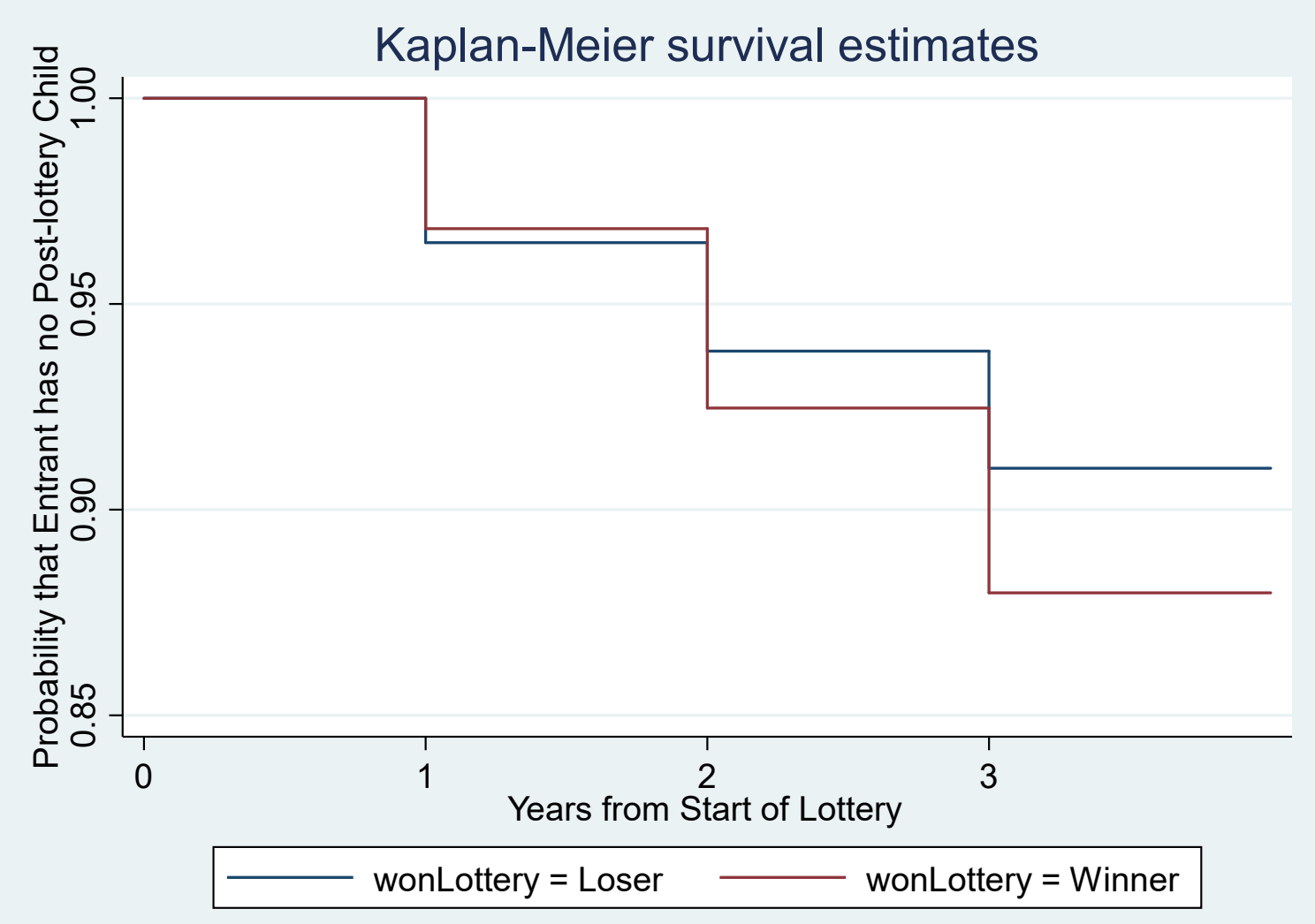


Notes: This figure plots the probability that an entrant has no post-lottery child in the years after 2011, the start of the lottery. Only lottery entrants are included.

Table 7. Cox Regressions on the Probability of Having a Post-lottery Child

(1)

(2)

(3)

\begin{tabular}{|c|c|c|c|}
\hline Won the Lottery & $\begin{array}{c}0.294 * * * \\
(0.112)\end{array}$ & $\begin{array}{l}0.214^{*} \\
(0.115)\end{array}$ & $\begin{array}{c}0.641 \\
(0.491)\end{array}$ \\
\hline $\begin{array}{l}\text { (Won the Lottery) } * \text { (Has } \\
\text { No Children Age } 4 \text { to } 18 \text { ) }\end{array}$ & & & $\begin{array}{l}-0.445 \\
(0.503)\end{array}$ \\
\hline $\begin{array}{l}\text { Has No Children Age } 4 \text { to } \\
18\end{array}$ & & & $\begin{array}{c}2.618^{* * *} \\
(0.218)\end{array}$ \\
\hline Age & & $\begin{array}{c}0.121 * * * \\
(0.032)\end{array}$ & $\begin{array}{c}0.352^{* * *} \\
(0.050)\end{array}$ \\
\hline$\left(\mathrm{Age}^{*}\right.$ age $)$ & & $\begin{array}{c}-0.002^{* * *} \\
(0.000)\end{array}$ & $\begin{array}{c}-0.005^{* * *} \\
(0.001)\end{array}$ \\
\hline Is male & & $\begin{array}{l}0.134^{*} \\
(0.006)\end{array}$ & $\begin{array}{c}0.060 \\
(0.073)\end{array}$ \\
\hline Entry Date Fixed Effects & No & Yes & Yes \\
\hline Education Fixed Effects & No & Yes & Yes \\
\hline$N$ & 7,851 & 7,851 & 7,851 \\
\hline $\begin{array}{l}\text { Effect of cars for entrants } \\
\text { with no children age } 4 \text { to } 18 \\
\text { (Row } 1+\text { Row } 2 \text { ) }\end{array}$ & & & $\begin{array}{l}0.196^{*} \\
(0.113)\end{array}$ \\
\hline
\end{tabular}

Notes: Results of hazard estimation, where the dependent variable is whether the lottery entrant had a pre-lottery child. Standard errors are clustered at the individual level.

$* p<0.10, * * p<0.05, * * * p<0.01$.

\subsubsection{Year-by-Year Effects on Births}


To check whether the number of post-lottery children born to lottery winners is large by historical standards, we examine the difference in the number of children born in each year between winning and losing households in Figure 7. Point estimates for 2013 and 2014 suggest that winning increases the number of children per entrant born in these years more than 0.02 percentage points; this point estimate is greater than the comparable point estimate for children born in any other year. The figure suggests that the lottery had a larger effect on fertility in 2013 and 2014 than in 2011 and 2012.

Figure 7. The Difference in the Number of Children between Winning and Losing Households by Birth Year

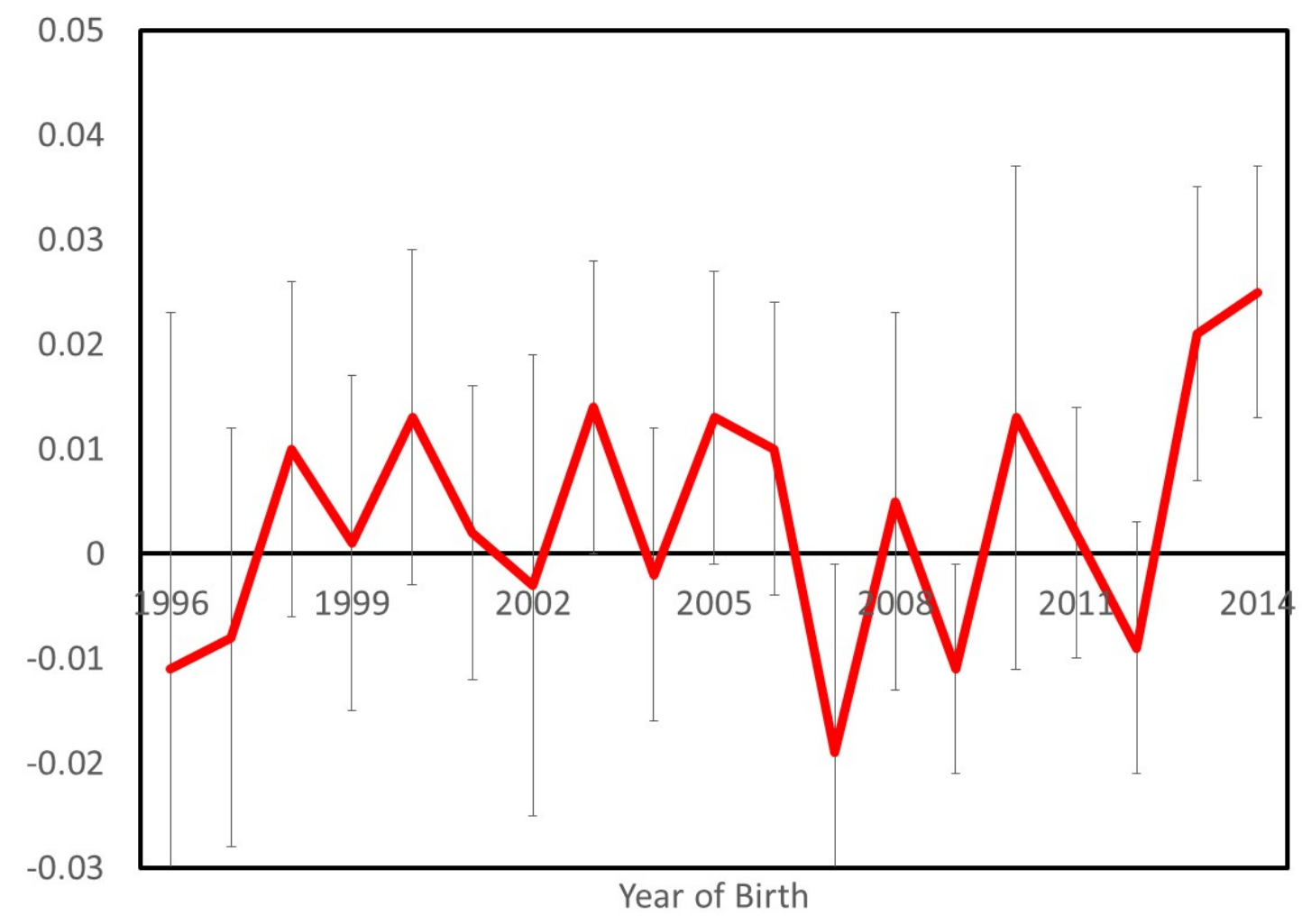

Notes: This figure plots the estimated coefficient $\alpha_{1}$ from equation (1), when the dependent variable is the number of children born in the year indicated. Only lottery entrants are included. Bars indicate two standard errors. 


\subsubsection{Robustness of Results to Application Renewals}

Beijing changed the rules for its lottery so that applications were removed if they did not submit periodic online renewals. ${ }^{12}$ Because renewing the lottery application is a potential source of endogeneity, we checked that renewals do not bias the results by running an IV specification where we instrument for the number of cars by whether entrants reported winning the lottery without having to renew their applications. These results, reported in Table 8, strongly support our prior findings of the large effects of car ownership on fertility and household structure. Using the new instrument, we also repeated the expanded specification with interaction terms as presented in Table 6 . We report these results in Table 9, finding that they also largely agree with the prior findings.

12 If an applicant entered the lottery in 2011 and did not win during a given month, that entry would remain in the pool of applicants for each drawing throughout the remainder of the year. In January 2012, Beijing changed the rules of the lottery so that applicants had to renew their applications every three months. In January 2014, the lottery began to be held every two months rather than monthly; as a result, applications to the lottery had a duration of six months before renewal was required. 
Table 8. IV Regressions of Equations (1) and (2) on Children and Family Structure, Where the Instrument Is Whether the Entrant Won without Renewing Lottery Application

\section{Regressions on Children Regressions on Family Structure}

$\begin{array}{ccccc}\begin{array}{c}\text { Number of } \\ \text { post-lottery } \\ \text { children }\end{array} & \begin{array}{c}\text { Number of } \\ \text { pre-lottery } \\ \text { children }\end{array} & \begin{array}{c}\text { Husband/ } \\ \text { wife/child }\end{array} & \begin{array}{c}\text { Husband/ } \\ \text { wife }\end{array} & \begin{array}{c}2 \text { grand- } \\ \text { parents/2 } \\ \text { adults/1 } \\ \text { child }\end{array} \\ \text { (1) } & (2) & (3) & (4) & \text { (5) }\end{array}$

\begin{tabular}{lccccc}
\hline Number of cars & $0.084 * * *$ & -0.002 & -0.001 & $-0.089 * * *$ & $0.058^{* *}$ \\
& $(0.023)$ & $(0.017)$ & $(0.034)$ & $(0.023)$ & $(0.028)$ \\
Age / 100 & -0.007 & $1.698 * * *$ & $1.150^{*}$ & -0.015 & $0.268^{*}$ \\
& $(0.424)$ & $(0.495)$ & $(0.633)$ & $(0.303)$ & $(0.160)$ \\
$($ Age * age) / 10,000 & -0.413 & $-2.071 * * *$ & $-1.672 * *$ & $1.077 * * *$ & $-0.503 * * *$ \\
& $(0.500)$ & $(0.570)$ & $(0.735)$ & $(0.415)$ & $(0.172)$ \\
Is male & $0.019 *$ & $-0.015 * *$ & -0.013 & 0.002 & 0.011 \\
& $(0.011)$ & $(0.006)$ & $(0.008)$ & $(0.010)$ & $(0.011)$ \\
$N$ & 8,057 & 8,057 & 8,057 & 8,057 & 8,057 \\
$R^{2}$ & 0.033 & 0.023 & 0.017 & 0.070 & 0.036
\end{tabular}

Notes: Estimation results of equations (1) and (2). In each regression, covariates also include fixed effects for the day of the week the entrant was interviewed and the education level of the entrant. The variable of interest is the number of cars in individual $i$ 's household. We instrument for this variable by whether the individual won the Beijing vehicle lottery within 6 months of entering it. Only lottery entrants are included. Columns 1 and 2 report the number of children born between 2011 and 2014 and between 2007 and 2010, respectively. Columns 3 through 5 present regressions where the dependent variable is a dummy for whether a lottery entrant's household has the makeup indicated in the column heading.

$* p<0.10, * * p<0.05, * * * p<0.01$. 
Table 9. IV Regressions of Equations (3) through (5) on Children and Family Structure, Where the Instrument Is Whether the Entrant Won without Renewing Lottery Application

\begin{tabular}{|c|c|c|c|c|}
\hline & \multicolumn{4}{|c|}{ Regressions on Family Structure } \\
\hline & $\begin{array}{l}\text { Number of } \\
\text { post-lottery } \\
\text { children } \\
\text { (1) }\end{array}$ & $\begin{array}{l}\text { Husband/ } \\
\text { wife/child } \\
\text { (3) }\end{array}$ & $\begin{array}{l}\text { Husband/ } \\
\text { wife } \\
\text { (3) }\end{array}$ & $\begin{array}{c}2 \text { grand- } \\
\text { parents } / 2 \\
\text { adults } / 1 \text { child } \\
\text { (5) }\end{array}$ \\
\hline Number of cars * & 0.030 & -0.029 & $-0.021 * *$ & 0.039 \\
\hline (No children age 4 to 18 ) & $(0.028)$ & $(0.075)$ & $(0.009)$ & $(0.057)$ \\
\hline \multirow[t]{2}{*}{ Number of cars } & $0.091 * *$ & 0.011 & $-0.072 * *$ & 0.031 \\
\hline & $(0.044)$ & $(0.081)$ & 0.037 & $(0.049)$ \\
\hline \multirow[t]{2}{*}{ No children age 4 to 18} & -0.071 & $0.219^{*}$ & -0.002 & $-0.609 * * *$ \\
\hline & $(0.063)$ & $(0.131)$ & $(0.002)$ & $(0.063)$ \\
\hline$N$ & 8,057 & 8,057 & 8,057 & 8,057 \\
\hline$R^{2}$ & 0.085 & 0.078 & 0.176 & 0.061 \\
\hline $\begin{array}{l}\text { Effect of cars for entrants with } \\
\text { no children age } 4 \text { to } 18 \text { (Row } 1 \\
+ \text { Row 2) }\end{array}$ & $\begin{array}{c}0.121 * * * \\
(0.030)\end{array}$ & $\begin{array}{c}-0.018 \\
(0.037)\end{array}$ & $\begin{array}{c}-0.093 * * * \\
(0.034)\end{array}$ & $\begin{array}{c}0.071 * * * \\
(0.023)\end{array}$ \\
\hline \multicolumn{5}{|c|}{$\begin{array}{l}\text { Notes: Estimation results of equations (3) through (5). In each regression, covariates also include } \\
\text { age, age-squared, a dummy for gender, fixed effects for the day of the week the entrant was } \\
\text { interviewed, and the education level of the entrant. The regression also includes the interaction of } \\
\text { each of these covariates with whether the entrant won the lottery. We instrument for the number } \\
\text { of cars and the interaction of the number of cars with whether the entrant had a child between the } \\
\text { ages of } 4 \text { and } 18 \text { using each of the above variables, along with whether the individual won the } \\
\text { Beijing vehicle lottery without having to renew the application, and the interaction of winning } \\
\text { with whether the entrant had a child between the ages of } 4 \text { and } 18 \text {. Only lottery entrants are } \\
\text { included. } \\
* p<0.10, * * p<0.05, * * * p<0.01 \text {. }\end{array}$} \\
\hline
\end{tabular}




\section{Conclusions}

Our estimated effects of vehicle ownership on fertility are statistically significant, large, and of economic importance. As we discussed in the introduction, these reductions are far larger than those found in the prior literature examining government policies that are intended to directly influence fertility, such as cash transfers, tax benefits, and paid time off for parents.

One implication of this paper is that vehicle ownership restrictions intended to address the environmental costs of cars have had a large unintentional social trade-off in the form of reducing fertility. Chinese municipalities concerned about the demographic structure of their cities should consider pairing vehicle restrictions with transportation options that may support childcare, such as family-friendly public transportation. A second implication is that projections of fertility rates should including changes in vehicle ownership rates, which we find play a strong role independent of income.

Regarding the implications of our results for other cities restricting or considering restricting car ownership, we note that Beijing has a high-quality public transportation system. Consequently, the effect of car ownership on childcare costs may be lower in Beijing than in other cities, suggesting that policies restricting ownership might have even larger effects elsewhere.

Whether the declines in fertility found in this paper are a temporary decrease or a permanent adjustment in births per woman is an important topic for future research. It is possible that women who win the lottery move their decision to have children forward in time or that 
frustrated lottery losers delay pregnancies. Even in this case, observed fertility for any given year in Beijing will be lower than it would have been as long as vehicle restrictions remain in place.

On the other hand, as we noted in the introduction, the OCP could mitigate the fertility effects of the vehicle restrictions during our sample. Recent changes to the OCP could therefore increase the effects of vehicle restrictions on fertility.

Our findings imply that transportation options play a powerful and previously unexplored role in family planning decisions. Policymakers concerned about declining fertility should consider strong incentives to offset these effects, such as transportation services targeted at families with young children.

\section{References}

Alfano, Marco. 2017. "Daughters, dowries, deliveries: The effect of marital payments on fertility choices in India." Journal of Development Economics 125: 89-104.

Becker, Gary S. 1960. "An Economic Analysis of Fertility." In Demographic and Economic Change in Developed Countries, 209-240. Princeton, NJ: Princeton Press.

Bharadwaj, Prashant. 2014. "Fertility and rural labor market inefficiencies: Evidence from India." Journal of Development Economics 115: 217-232.

Brainerd, Elizabeth. 2014. "Can government policies reduce undesirable declines in fertility?" IZA World of Labor 23: 1-10. 
Cameron, L., N. Erkal, L. Gangadharan, and X. Meng. 2013. "Little Emperors: Behavioral Impacts of China's One-Child Policy." Science 339 (6122): 953-957.

Coen-Pirani, Daniele, Alexis Leon, and Steven Lugauer. 2010. "The effect of household appliances on female labor force participation: Evidence from microdata." Labour Economics 17: 503-513.

D'Addio, Anna Cristina, and Marco Mira d'Ercole. 2005. "Policies, Institutions and Fertility Rates: A Panel Data Analysis for OECD Countries." OECD Economic Studies 41: 7-43.

Ding, Qu Jian, and Therese Hesketh. 2006. "Family size, fertility preferences, and sex ratio in China in the era of the one child family policy: results from national family planning and reproductive health survey." BMJ 333: 371-373.

Ebenstein, Avraham. 2010. "The "Missing Girls" of China and the Unintended Consequences of the One Child Policy." The Journal of Human Resources 45 (1): 87-115.

Feng, Wang. 2012. "Racing towards the precipice." China Economic Quarterly June: 17-21.

Gauthier, Anne Helene, and Jan Hatzius. 1997. "Family Benefits and Fertility: An Econometric Analysis." Population Studies 51 (3): 295-306.

Greenwood, Jeremy, Ananth Seshadri, and Mehmet Yorukoglu. 2005. "Engines of Liberation." Review of Economic Studies 72: 109-133. 
Kalwij, Adriaan. 2010. "The Impact of Family Policy Expenditure on Fertility in Western Europe." Demography 47 (2): 503-519.

Lee, Ronald, and Andrew Mason. 2014. "Is low fertility really a problem? Population aging, dependency, and consumption." Science 346 (6206): 229-234.

Liu, Antung A., Joshua Linn, Ping Qin, and Jun Yang. 2017. "The Effect of Vehicle Restrictions on Female Labor Supply." Working Paper.

Osili, Una O., and Bridget T Long. 2008. "Does female schooling reduce fertility? Evidence from Nigeria." Journal of Development Economics 87: 57-75.

UN (United Nations). 2017. World Population Prospects. New York: UN.

Viard, V. Brian, and Shihe Fu. 2015. "The effect of Beijing's driving restrictions on pollution and economic activity." Journal of Public Economics 125: 98-115.

Wang, Lanlan, Jintao Xu, Xinye Zheng, and Ping Qin. 2013. "Will a Driving Restriction Policy Reduce Car Trips? A Case Study of Beijing, China." Environment for Development Discussion Paper Series EfD DP 13-11.

Willis, Robert J. 1973. "A New Approach to the Economic Theory of Fertility Behavior." Journal of Political Economy 81 (2): S14-S64.

Yang, Jun, Antung A. Liu, Ping Qin, and Joshua Linn. 2017. "The Effect of Vehicle Restrictions on Travel Behavior: Evidence from the Beijing License Plate Lottery." Working Paper. 
Yang, Jun, Ping Qin, Ying Liu, and Antung A. Liu. 2014. "A review of Beijing's vehicle registration lottery: Short-term effects on vehicle growth and fuel consumption." Energy Policy 75: 157-166.

Zhang, Junsen. 2017. "The Evolution of China's One-Child Policy and Its Effects on Family Outcomes." The Journal of Economic Perspectives 31 (1): 141-160.

Zhong, Nan, Jing Cao, and Yuzhu Wang. 2017. "Traffic Congestion, Ambient Air Pollution, and Health: Evidence from Driving Restrictions in Beijing." Journal of the Association of Environmental and Resource Economists 4: 821-856. 